\title{
Corruption Control, Renewable-led Energy Transition and Carbon Emissions: Empirical Evidence from Panel Data of Multi-countries
}

\author{
Yongpei Wang ( $\nabla$ wang_yongpei@139.com ) \\ Nanjing Audit University https://orcid.org/0000-0001-5533-8656 \\ Jieru Yang \\ Nanjing Audit University
}

\section{Research Article}

Keywords: Anti-corruption Mediating effect, Renewable energy, Carbon emissions, Energy transition

Posted Date: November 9th, 2021

DOl: https://doi.org/10.21203/rs.3.rs-916371/v1

License: (c) (1) This work is licensed under a Creative Commons Attribution 4.0 International License.

Read Full License 
1 Corruption control, renewable-led energy transition and carbon emissions: 2 Empirical evidence from panel data of multi-countries

\author{
Yongpei Wang ${ }^{\mathrm{a}, \mathrm{b}^{*}}, \quad$ Jieru Yang ${ }^{\mathrm{a}}$
}

$4 \quad{ }^{a}$ School of Economics, Nanjing Audit University, Nanjing 211815, P.R. China

$5 \quad{ }^{b}$ School of Urban and Regional Science, Shanghai University of Finance and Economics, Shanghai 200433, P.R. China

6 E-mail addresses: wang_yongpei@139.com(Y.Wang),mg2006225@stu.nau.edu.cn(J.Yang)

$7 \quad$ *Corresponding author: wang_yongpei@139.com(Y.Wang)

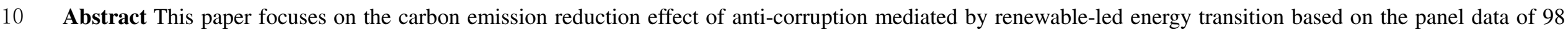

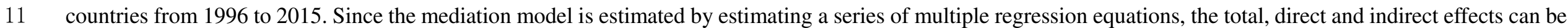

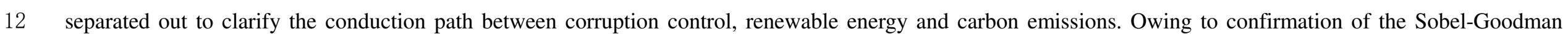

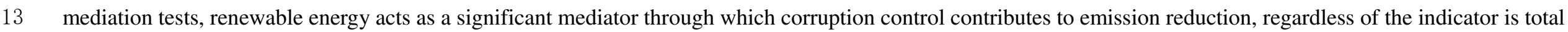

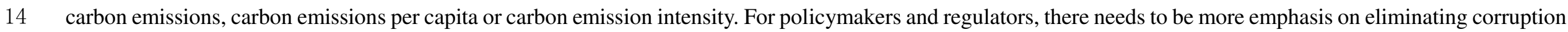

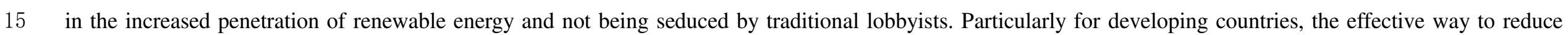

16 emissions is to remove institutional barriers in priority areas including the energy and resources sectors to cleaner-oriented energy transition. 


\section{Introduction}

As the global warming caused by the continuous accumulation of greenhouse effect is becoming increasingly serious, and has even threatened the sustainability of

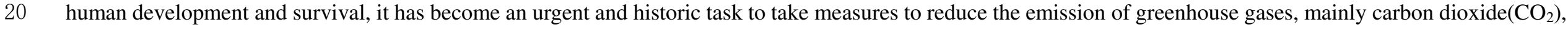

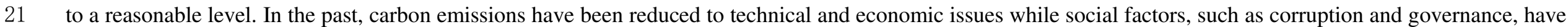

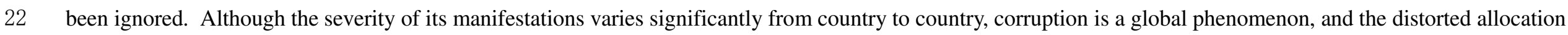

of resources it causes is the root cause of many social problems(Cole, 2007; Fredriksson and Svensson, 2003; De Jong and Bogmans, 2011). Resource-intensive and capital-intensive industries are often hard hit by corruption(Kolstad, et al., 2008). The energy sector is resource-intensive and capital-intensive, so it is easy to imagine the endless corruption cases(Gisladottir et al., 2020). For example, in China, many of the most egregious cases of corruption have occurred in the energy sector, which has not only caused serious economic losses, but also harmed environmental governance and improvement(Hao et al., 2020).

Ever since the Paris climate agreement in 2015 , in which 195 countries pledged to limit global temperatures to no more than $2^{\circ} \mathrm{C}$ above pre-industrial levels and do their best to limit rises to around $1.5^{\circ} \mathrm{C}$, energy transition has become synonymous with the future of energy. It is the general trend of the world energy transformation to implement clean substitution on the energy supply side and electric energy substitution on the energy consumption side, so as to form an energy pattern dominated by clean energy and centered on electricity. Major countries in the world have simultaneously accelerated the development of low and decarbonization energy systems.

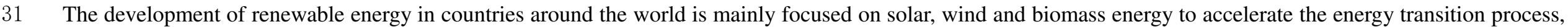



mainly reflected in the shift of energy investment focus to green and clean energy, and the further optimization of industrial structure and energy consumption structure. Developed countries in Europe and the United States have put forward clear energy transition plans and measures, which is an important pilot signal of the profound changes in the international energy system under the background of new scientific and technological revolution, climate change and green and low-carbon environment.

Corruption, however, has become a major obstacle to the energy transition. Bribery and corruption cost the world economy at least $\$ 1.5$ trillion annually, about 2 percent of global GDP, which could have been used to eradicate poverty, create jobs and protect the environment(IMF,2016). A widening gap in environmental regulation would amplify the impact of trade convergence, forcing polluting firms to move to polluting havens. After decades of globalization, some countries, especially developing and emerging economies, have moderate levels of regulatory corruption that attract polluters to move in, and the existence of traditional lobbies makes pollution havens and corruption paradise suitable for some European companies(Candau and Dienesch, 2017). Polluting corporate lobbies still have ample bribe capital to influence the quality of environmental policy implementation. When there is a certain level of corruption, the quality of environmental policy implementation will be the balanced result of the game between various interest groups, which cannot make up for the negative externalities caused by environmental pollution.

In this paper, we estimate the total and intensity effects of corruption control on carbon emissions by using multi-country panel data and instrumental variable method. Different from the previous literature, considering that increasing the share of renewable energy and reducing the dependence on fossil energy are the basic ways of environmental pollution, we study the corresponding mediating effect, that is, how corruption affects renewable energy and then carbon emissions. We adopt the fixed effect model of instrumental variables to eliminate the errors caused by endogeneity. High income countries, middle-income countries and low-income countries show obvious heterogeneity in corruption control. In order to ensure the robustness of the parameters, we make group estimation and draw more enlightening conclusions. 


\section{Literature review}

Whether in developed or developing countries, corruption is a difficult problem to eradicate. Corruption is the main obstacle to growth and development. Corruption reduces investment, weakens a country's ability to attract foreign investment and adversely affects capital accumulation, thereby reducing economic growth (Mauro 1995; Lambsdorff 2003; Dutta et al. 2017). Brunetti and Weder (1998) presented evidence of the link between economic growth and "rule credibility", they found that changes in two uncertain indicators (rule of law and corruption) have the greatest impact on investment. Xu and Yano (2017) used detailed data of listed companies in China from 2009 to 2015 to investigate the impact of anti-corruption on innovative financing and investment, and found that anti-corruption makes companies more likely to obtain external funds. In addition, some scholars have found that the degree of corruption is related to the degree of income inequality and ethnic differentiation (Glaeser and Saks 2006), and corruption also usually hinders international trade (De and Bogmans 2011). Corruption conforms to the standard economic incentive theory, but the effect of anti-corruption policies tends to weaken as officials find alternative strategies to pursue rents (Olken and Pande 2012).

At the same time, environmental pollution and ecological damage are becoming more and more serious around the world. In particular, studies have found that air pollution is extremely harmful to human health (Kampa and Castanas 2008). Green mountains and lucid waters are indeed mountains of gold and silver, and environmental improvement means greater productivity. A sound environment promises great economic potential, generates good returns, and contributes to economic and social sustainability. Eco-environmental protection is imminent. In recent years, China has increased its efforts in anti-corruption and environmental protection. Corruption and pollution have long been the focus of attention of scholars, and the academic circle has launched a lot of research on corruption and pollution.

Most scholars have concluded that corruption will worsen the environment through empirical analysis (Liu and Dong 2021; Zhang et al. 2016; Hassaballa 2015). Sulemana and Kpienbaareh (2020) studied the link between corruption and air pollution in Africa and OECD countries. They found that corruption can lead to an 

study the relationship between environmental decentralization, government corruption and air pollution. They found that local government corruption weakens the effect of local environmental decentralization on air pollution. Some scholars have also found that there is a dynamic relationship between corruption and pollution. Based on panel data from 30 provinces in China from 2002 to 2017, Yang et al. (2020) used the spatial Dubin model to find that regional corruption has a dual effect on carbon emissions. Corruption and carbon emissions present an $\mathrm{N}$-type dynamic relationship, that is, regional corruption tends to aggravate carbon emissions first, then help reduce carbon emissions, and finally increase carbon emissions gradually. Cole (2007) selected data from 94 countries from 1987 to 2000 to study the relationship between corruption and $\mathrm{SO}_{2}$ and $\mathrm{CO}_{2}$ emissions per capita, and found that excluding some high-income countries, corruption does not lead to an increase in pollution.

Regarding the mechanism of corruption on pollution, the impact of corruption on pollution can be divided into direct and indirect effects. The impact of corruption on pollution ultimately depends on the combined effects of direct and indirect effects. Through empirical analysis, the direct impact of corruption on the environment is mostly positive. Its mechanism is that corruption will lead to sub-optimal environmental governance, which will delay the formulation of environmental policies, reduce the strictness and effectiveness of environmental regulations, and weaken the intensity of environmental supervision, thus leading to the deterioration of environmental quality and the intensification of pollution (Pellegrini and Gerlagh 2006; Walter and Luebke 2013; Fredriksson and Svensson 2003; Candau and Dienesch

2017). Polluting companies in countries with serious corruption problems often conceal the discharge of some pollutants to the government, so as to achieve the purpose of paying less environmental taxes (Ivanova, 2011). While corruption reduces the strictness of environmental policies, the effect of environmental policy demands also depends on the degree of corruption, which leads to a vicious circle of corruption and pollution (Damania et al., 2003). In addition, the increase in air pollution will 


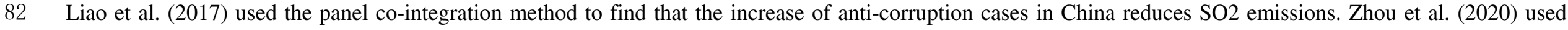

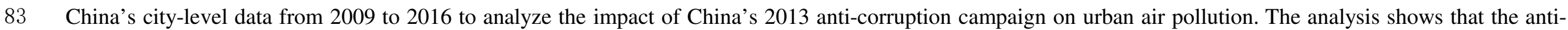
corruption campaign can not only directly reduce pollution levels, but also indirectly reduce pollution through improving the intensity of environmental regulations and the level of economic development. The anti-corruption movement is more of an external shock, which is more objective than the shock form of studying the change of official positions in previous literature. At the same time, the study found that the pollution reduction effect of the anti-corruption campaign is more significant in China's resource-based cities, northern cities and western regions.

The indirect effects of corruption on pollution are studied by scholars from the perspectives of economic development level, hidden economy and resource allocation, etc. Scholars have different conclusions about the indirect effects of corruption on pollution. Based on the intermediate variable of income per capita, Welsch (2004) discussed this indirect effect for the first time, but the author did not control the potential endogeneity between income and corruption and did not consider the heterogeneity of different countries. Cole (2007) overcome these two problems. Based on the data of 94 countries from 1987 to 2000 , Cole constructed two joint equations in which corruption and pollution are mutually causal variables. Through analysis, it was found that the direct impact of corruption on $\mathrm{SO}_{2}$ and $\mathrm{CO}_{2} \mathrm{emissions}$ per capita is positive, but the indirect impact based on income is negative, and the absolute value of indirect impact is greater than that of direct impact. Except for some high-income countries, the total effect of corruption on pollution is negative, that is, corruption will not lead to an increase in pollution level. In contrast, when Rehman et al. (2012) studied the existence of the environmental Kuznets curve in some countries in South Asia from 1984 to 2008 , they found that at a given income level, when the degree of corruption increases, pollution emissions also increase. The degree of corruption is positively correlated with the critical income level corresponding to the environmental Kuznets curve. Based on the intermediate variables of GDP, Jabeu and Sghaier (2018) found that the direct impact of corruption 

development, and low economic development reduces $\mathrm{CO}_{2}$ emissions.

A considerable part of the research on the intermediate variable of income is related to the environmental Kuznets curve. Grossman and Krueger (1991) discovered the environmental Kuznets curve for the first time. Taking the corruption factor into consideration, the environmental Kuznets curve still holds (Lisciandra and Migliardo 2017; Sahli and Rejeb 2015). However, the existence of corruption will cause the turning point of the environmental Kuznets curve to move backward, that is, the turning point will appear at a higher per capita income level and pollution level (Lopez and Mitra 2000). Moreover, the higher the degree of corruption, the greater the deviation between the actual path of income and pollution and the social optimal path without corruption factors (Leitão 2010).

Corruption can also affect the quality of the environment by affecting the hidden economy. Blackman (2000) discovered that hidden economic activities can seriously damage the quality of the environment. Corruption exacerbates the destructive effects of the hidden economy (Biswas et al. 2012). Based on the provincial panel data from 1998 to 2017 in China, Wang et al. (2019) analyzed the interaction of local government corruption and hidden economy on environmental pollution by using MIMIC and spatial econometric models, and found that corruption can increase pollutant emissions by expanding the scale of hidden economy. The increase in the number of corrupt officials has reduced the penalty cost of pollution discharge in the informal sector, which makes polluting enterprises turn their production activities to the informal sector to obtain higher profits, thus expanding the scale of the hidden economy and further increasing the emission of pollutants. Based on the perspective of resource allocation to study the impact of corruption on pollution, Hao et al. (2020) used panel data from 30 provinces in China from 2005 to 2016 to study the relationship between mismatch, corruption and green total-factor energy efficiency. Research shows that corruption worsens resource allocation and improper allocation of resources further inhibits green all-factor energy efficiency. There are many ways for the indirect impact of corruption on pollution. For example, Tang et al. (2020) 


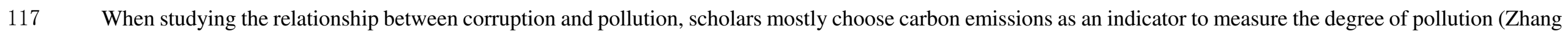
et al. 2016; Hassaballa 2015; Yang et al. 2020; Cole 2007; Rehman et al. 2012; Jabeur and Sghaier 2018). In addition, scholars also choose SO2 emissions (Liao et al. 2017; Cole 2007), green total factor energy efficiency (Hao et al. 2020), environmental sustainability index (ESI) (Morse 2006) and PM2.5 concentration (Liu and Dong 2020) and other indicators. The best way to measure corruption is to directly observe the bribery of officials, but the bribery behavior of officials is generally more obscure, so it is not easy to be observed. The indicators commonly used by scholars when measuring corruption are: Transparency International's Corruption Perception Index (CPI), the World Governance Index (WGI) adopted by the World Bank, and the International Corruption Risk Index (ICR) of the Political Risk Service Group. Most scholars use the CPI index (Biswas et al. 2012; Morse 2006; Liu and Dong 2020) when measuring the degree of corruption. In addition, Glaeser and Saks (2006) used the number of civil servants accused of abuse of power to measure corruption when investigating the link between corruption and economic growth in different states in the United States. Wang et al. (2020) used a spatial econometric model to study the interactive effects of corruption and foreign direct investment (FDI) on environmental pollution based on panel data from 29 provinces and cities in China from 1994 to 2015 . In order to exclude the influence of the size of the government and the total population of the region, the author used the ratio of the number of official crime cases to the number of public officials and the ratio of the number of official crime cases to the total population as indicators of corruption.

Most of the existing research on corruption focuses on its impact on economic development. There is still a lack of discussion on the relationship between corruption 


\section{Methodology and data}

\subsection{Mediation effect model} Ramón and Mitra,2000; Yap, 2006; Liu and Dong, 2021), and its impact on energy consumption has also been well documented(Cadoret and Padovano, 2016; Stern, 2012; Sekrafi and Sghaier, 2016), the sequential conduction route of corruption, renewable-led energy transition and carbon emissions has not been clarified(Nicolli and Vona, 2015). Theoretically, as presented in Fig.1, there are two accessory pathways from corruption to carbon emissions, one is directly acting on carbon emissions, the other is indirectly acting through the renewable-led energy transition, in which the renewable-led energy transition plays a mediating role. The increasing material wealth of mankind has driven economic growth at the cost of energy consumption. The polluting nature of fossil fuels requires that they be replaced by clean and renewable energy sources. But in this process, the short-sighted behavior of established interest groups, corrupt practices such as bribery and collusion, impede the clean-oriented energy transition. Specifically, in this paper, in the middle of the relationship between corruption and carbon emissions, the share of renewable energy in total energy consumption serves as a mediator. These mediating effects are assessed by estimating the following equations:

$$
\begin{aligned}
& E_{i t}=\alpha+\beta \operatorname{Corr}_{i t}+\sum_{n=1} \varphi_{n} X_{i t}+\varepsilon_{i t} \\
& \operatorname{Ren}_{i t}=\alpha+\gamma \operatorname{Corr}_{i t}+\sum_{n=1} \varphi_{n} X_{i t}+\mu_{i t} \\
& E_{i t}=\alpha+\beta^{\prime} \operatorname{Corr}_{i t}+\lambda \operatorname{Ren}_{i t}+\sum_{n=1} \varphi_{n} X_{i t}+v_{i t}
\end{aligned}
$$


where $E_{i t}$ refers to the corban emissions of country $i$ at year $t$, which can be numerically expressed as total carbon emissions $(C O)$, carbon emission per capita( $\left.C O P\right)$ and carbon emission intensity $(C O I)$,respectively. $\operatorname{Corr}_{i t}$ denotes is the annual corruption control index of the evaluated country. Ren it $_{\text {is }}$ share of renewable energy in total energy consumption. $X_{i t}$ is the set of control variables, including GDP per capita $\left(g d p p_{i t}\right)$, the proportion of industrial added value in total output value $\left(i n d_{i t}\right)$, the share of fossil energy in total energy consumption $\left(f o s_{i t}\right)$, and the share of net energy import in energy use $\left(n i m m_{i t}\right) . \varepsilon_{i t}, \mu_{i t}$ and $v_{i t}$ are the error terms of the corresponding equations. The estimated coefficient $\beta$ presented in Eq.(1) and Fig.1 should be referred to as the total effect of corruption control on carbon emissions, which is distinguished from the estimated coefficient $\beta^{\prime}$ in Eq.(3) that represented as the direct effect of corruption control on carbon emissions after controlling for the share of renewable energy. The mediational effect, in which corruption control leads to carbon emissions through the share of renewable energy, is called the indirect effect, which represents the portion of the relationship between corruption control and carbon emissions that is mediated by renewable-led energy transition. At first, a four step approach proposed by Baron and Kenny (1986) which tends to miss some true mediational effects(MacKinnon et al., 2007). However, turning to the equivalent approach calculates the indirect effect by subtraction between the total effect and the direct effect of the two regression coefficients in Eq.(1) and Eq.(3) as following,

$$
\beta_{\text {indirect }}=\beta-\beta^{\prime}
$$

The goal of conducting mediation analysis is to indirectly assess the effect of a proposed cause on dependent variable through a proposed mediator. The utility of mediation analysis stems from its ability to go beyond just describing the relationships between variables to understanding the relationships between variables. A necessary component of mediation is that indirect effects are statistically and practically significant(Preacher and Hayes, 2004). Thus, in this paper, we apply the SobelGoodman tests to inspecting whether renewable-led energy transition performance as the mediator that carries the influence of corruption control on carbon emissions. Once the coefficient of the indirect effect has been estimated, its significance needs to be tested. In particular, the mediating effect in this paper can be said to occur 


\subsection{Data descriptions}

The panel data used in this paper generally comes from the world development indicators (WDI) of the World Bank, which is compiled from officially recognized international sources. As for carbon emissions, they are statistically derived from the burning of fossil fuels and the manufacture of cement, including solid, liquid and gaseous fuels as well as natural gas. In addition to total carbon emissions, per capita carbon emissions and carbon intensity are also used as dependent variables. The corresponding variable definitions, units of measurement and statistical descriptions are presented in Table 1 . Viewed from different angles, the global pattern of carbon emissions has shifted significantly in recent years. As shown in Fig.2, in terms of total volume of carbon emissions, China and the United States constitute the two largest emitters, and when it comes to per capita emissions, high-income countries such as Europe and the United States are the key players. On the contrary, from the middle-income countries taking the top position. 
For mediation variables, in this paper, it specifically refers to the share of renewable energy consumption in the total final energy consumption labeled by Ren. Due

to the limitation of resource endowment, technical conditions and absorption mechanism, there are obvious differences in renewable energy among countries.

Statistically speaking, the value of the index is between 0 and $98 \%$, which means that some countries have negligible renewables, while others derive almost all their energy consumption from renewables. In terms of countries, it can be seen from Fig. 3 that the higher penetration of renewable energy is mainly distributed in regions such as Africa and Northern Europe. In addition, we also provide a set of control variables, the main purpose of which is to control income level, industrial structure, proportion of fossil energy and energy import dependence, etc. The statistical description and global distribution of these variables are shown in Table 1 and Fig. 3 respectively. From the conduction mechanism of various variables and multicollinearity of variables, the correlation coefficient between variables should be within a reasonable range( see Table 2), not too high to lead to multicollinearity, nor too low to lack of basic statistical correlation.

Table 2 Correlation coefficients 
measure the level of government administration. The WGI is a research data set that summarizes the views of a large number of respondents from enterprises, citizens and experts in industrial and developing countries on the quality of governance. The data come from a number of research institutions, think tanks, non-governmental organizations, international organizations and private enterprises. Among them, corruption control observes the extent to which public power is exercised for selfinterest, including large and small forms of corruption, and the occupation of national resources by the elite and private interests. In terms of the index itself, the higher the value indicates that the better the country controls corruption, and the lower the corruption level. Overall, corruption control continues to improve in most countries, despite the huge gap between high-income and low-income countries. Corruption leads to the distortion of renewable and non-renewable energy resources allocation, which affects the carbon emission situation. However, whether it meets the significance needs to be tested by the above methods.

\section{Empirical results}

\subsection{Basic results}

Before the Sobel-Goodman mediation test, we first estimate the total effect of corruption control on carbon emissions under path $\beta$, the results of which are presented in Table 3. Since there are three measurement methods of carbon emission in this paper, namely total carbon emissions, per capita carbon emissions and carbon emission intensity, their respective estimation parameters can be obtained. For the total effect, The estimated coefficient of $C O$ is significantly negative, and one unit increase in the corruption control indicator will reduce total carbon emissions by about $39.1 \%$, indicating that from the perspective of total effect, corruption control can reduce total carbon emissions, and reducing corruption is an important way to reduce pollution emissions. The $C O$ reflects the overall situation of a country's carbon emissions. 

carbon emissions per capita by $15.2 \%$. Turning to carbon emission intensity, the total effect is basically consistent with the former two $(C O$ and $C O P)$, and even the estimated coefficients of $C O I$ and $C O P$ are very close, although their global distribution based on quantity varies greatly. In general, corruption control has an effective negative effect on carbon emissions from the perspective of total volume, per capita and intensity, which shows that path $\beta$ is positive and feasible. Restraining corruption can reduce pollution in both absolute and relative quantity, which fully shows that anti-corruption is an important way to reduce emissions, and in turn explains as it is proposed by Candau and Dienesch (2017) that why some low-income countries are both pollution havens and corruption paradise.

Regarding the path $\gamma$ which reflects the impact of anti-corruption on renewable energy consumption, although major countries in the world have set medium- and long-term renewable energy consumption share targets, and even some countries have put forward 100\% renewable energy planning for carbon neutralization, and technological development has led to a significant reduction in the cost of renewable energy production, institutional and governance deficiencies that plague renewable energy remain, notably widespread corruption. The estimated coefficients of the corruption control indicator in Table 4 illustrate this situation, which is significantly 

existence of mediating effect. More specifically, at the $1 \%$ significance level, one unit increase in the corruption control indicator will lead to a $25 \%$ increase in the share of renewable energy consumption.

In considering the direct effect of corruption control on carbon emissions, both the independent variable Corr and the mediator Ren should be introduced into the econometric model. The estimated coefficients in Table 5 can show whether paths $\beta^{\prime}$ and $\lambda$ is effective. Consistent with the previous estimation parameters, the coefficient of $\operatorname{Corr}$ meets the significance requirement of $1 \%$, and the value is as negative as expected. However, for different indicators of carbon emissions, the estimated parameters are slightly different. When the carbon emission indicator is the total carbon emissions, the estimated coefficient is -0.3321 , that is to say, one unit increase of corruption control indicator will reduce the total carbon emissions by about $33.2 \%$, and the role of anti-corruption in reducing emissions has been confirmed again. In comparison, if the total carbon emissions are replaced by the carbon emissions per capita, the sign and significance level of the estimation coefficient do not change, but only the value of the parameters to be estimated. The estimated coefficient of Corr is reduced to 0.1052 , which indicates that the increase of corruption control index of a unit reduces the per capita carbon emission by about $10.5 \%$. The same situation occurs when the carbon emission index is replaced by $C O I$, which further confirms the significance of the direct effect. With regard to path $\lambda$, regardless of whether the dependent variable is $C O$, $C O P$ or COI, the estimated coefficients of Ren are all significantly negative, indicating that increasing the share of renewable energy consumption is conducive to the realization of emission reduction targets. In addition, it is necessary to mention that this paper introduces a number of control variables in the model, most of their estimated coefficients are in line with expectations, but the sign of GDP per capita in the intensity model is contrary to expectations, which may be related to the environmental Kuznets curve. 
Since the path $\beta, \lambda$ and $\beta^{\prime}$ are significantly effective, the Sobel-Goodman mediation test presented in Table 6 can be further used to characterize the mediating effect, because there are requirements not only for sign of the direct effect, but also for significance of the direct effect. As far as $C O$ is concerned, the statistics of Sobel, Goodman-1 and Goodman-2 all meet the significance requirement at $1 \%$, which confirms the feasibility of renewable energy consumption share as the intermediary of corruption control and total carbon emissions. The specific value of the indirect effect is -0.0587 , that is to say, the increase of corruption control indicator by one unit not only reduces the total carbon emissions by $33.2 \%$ directly, but also reduces the total carbon emissions by $5.87 \%$ indirectly through the intermediary role of the share of renewable energy consumption in the total final energy consumption. When the dependent variable is replaced by $C O P$, the significant indirect effect also indicates Ren as a mediator. Furthermore, the indirect effect coefficient of carbon emissions per capita shows that the mediator contributes about $4.7 \%$ to the decrease of carbon emissions per capita. Once the dependent variable is replaced by COI, not only the mediating effect is supported by all statistics, but transition and play a positive role in carbon emission reduction.

\subsection{Robustness checks}



reports the regression results of fixed-effects(FE) and fixed-effects IV(FE-IV) method. Although the estimated coefficients are different from the previous ones mentioned above, there are no significant differences in sign and significance. The two main variables, Corr and Ren, are negatively correlated with carbon emission indicators, which further shows that anti-corruption and renewable-led energy transition can promote emission reduction. We selected the lag term of corruption control indicator as its instrumental variable to examine the robustness of path $\beta^{\prime}$ and $\lambda$. The results of the last three columns in Table 6 show that there is no obvious mutation in sign and significance for Corr and Ren, and the direct effect is statistically significant. Furthermore, considering the outstanding heterogeneity between highincome countries and low- and middle-income countries, we divide the study sample into high-income groups and low-and middle- income groups for group regression, and the results are shown in Table 8 . An obvious difference is that the Corr estimation coefficient of the high-income countries does not meet the significance requirement under the three carbon emission indicators. On the contrary, the corresponding estimated coefficients for low- and middle-income countries show a high degree of consistency with the above estimated parameters, indicating that the robustness can be guaranteed, and the emission reduction effect of anti-corruption is mainly contributed by developing countries. 

emission reduction effect of increasing the share of renewable energy consumption has universal significance. For high-income countries, the estimation coefficient shows that, on average, a $1 \%$ increase in the share of renewable energy consumption can reduce the total carbon emissions, carbon emissions per capita and carbon emission intensity of these countries by about $0.12 \%, 0.11 \%$ and $0.10 \%$ respectively. Comparably, taking into consideration of low- and middle- income countries, the estimation coefficient of Ren indicates that a $1 \%$ increase in the share of renewable energy consumption may evenly reduce the total carbon emissions, carbon emissions per capita and carbon emission intensity by about $0.3 \%$ respectively. The main trend of the global energy transition is the overall improvement of energy efficiency and the large-scale development and utilization of renewable energy. Due to the differences in resource endowment, energy strategy and technological level, developed and developing countries have embarked on different paths of energy transition. Under the premise of pursuing energy independence, the representative developed countries take the lead in promoting the large-scale application of renewable energy and promoting the clean-oriented energy mix, with natural gas and renewable energy as leading energy. In view of the political and economic transition of energy, developing countries have also joined the global energy transition, including controlling total energy consumption, increasing the supply of non-fossil energy, and promoting energy conservation and emission reduction as the main measures, making outstanding contributions to the global energy transition.

\section{Conclusions and policy implications}



originating from the database of World Bank, which are total carbon emissions $(C O)$, carbon emissions per capita( $C O P)$ and carbon emission intensity $(C O I)$. The independent variable is the corruption control indicator, while the mediator is the share of renewable energy consumption in total final energy consumption. The sample data is made up of 98 countries from 1996 to 2015, covering major developed and developing countries, and is therefore adequately representative. In view of the past experience in the relationship between anti-corruption, energy transition and environmental pollution in various countries, the energy and environment sectors are the hotbeds for corruption(Kolstad et al.,2008), especially for low- and middle-income countries, corruption paradise and pollution haven are often accompanied by each other. Corruption has both direct effects and indirect effects mediated by renewable energy on environmental pollution, and the significance of these effects is precisely the purpose of this study using the mediation effect model.

Some meaningful findings can be obtained from the empirical analysis of this paper as follows: First of all, anti-corruption can restrain carbon emissions to a certain extent, especially for low - and middle-income countries. Due to the long-term implementation of deindustrialization, a large number of high polluting enterprises are transferred and dispersed to developing countries and emerging markets with low intensity of environmental regulation, and the rent-seeking space of high-income countries is greatly compressed, thus the corruption problem is relatively light. The relationship between corruption and carbon emissions in these countries is less prominent than that in developing countries. Whether it is corruption or environmental pollution, developing countries are more serious, and even some problems have become a persistent disease hindering sustainable development, because their pollution haven is often shaped by corruption with embeddedness of high pollution enterprises (Damania, 2002;Barassi and Zhou, 2012; Egger and Winner, 2005;Sarmidi, et al., 2015). In the developing and emerging economies, only a few countries, such as China, have taken measures to break the link between corruption and pollution. The mode of co-existence of corruption and pollution is still difficult to be 
empirical evidence for renewable energy as a mediator between corruption control and carbon emissions. The similar indirect effects obtained from the three carbon emission indicators indicate that the mediating effect of renewable-led energy transition is certain. Corruption is seen as one of the biggest threats to effective climate action and a major obstacle to the global transition from fossil fuels to renewable energy (Oniango, 2020). The threat of corruption to renewable energy is not only rampant in developing countries and emerging markets, but even in advanced economies such as Italy (Gennaioli and Tavoni, 2016) and Iceland(Gisladottir et al., 2020), the risk of corruption in the renewable energy sector is difficult to avoid. Additionally, only when the total, direct and indirect effects are significant and the corresponding numerical conditions are met, can the conduction paths of corruption control, energy transition and carbon emissions be considered to be unimpeded. In addition to the Sobel-Goodman mediation tests of three carbon emission indicators, the estimation method that introduce instrumental variables to eliminate endogeneity may be beneficial to supporting the mediating effect of renewable energy between corruption and carbon emissions.

These findings imply that leaving corruption monitors absent increases the risk of corruption in both the non-renewable and renewable resource sectors, thereby hampering sustainable management of renewable resources and the environment. Anti-corruption policies need to be adequately enforced during the energy transition. For countries with abundant renewable natural resources, measures should also be taken to address the underlying situation of current mismanagement. Relevant policy optimizations should include collaboration between government agencies, businesses and local resource users and other actors to avoid collusive behavior by emitters. For developing and emerging markets, it is necessary to improve market access for resource-intensive businesses without interference from interest group lobbying and bribery, and to insist on higher standards of environmental regulation. Give up lax environmental policies and fill the gap in environmental regulation, regardless of short-term monetary losses. In general, the affected countries will have to transform the functions of government, improve the institutional framework of integrity, strengthen the capacity of the supervision institutions, and develop reasonable and monitoring mechanisms to curb the breeding and spread of corruption, so as to improve the quality of environmental policies. 
Ethics approval and consent to participate: The present study work was not conducted on human or experimental animals where national or international guidelines are used for the protection of human subjects and animal welfare. Hence, ethics approval and consent to participate are not applicable.

Consent for publication: We confirm that the manuscript has been read and approved by all named authors and that there are no other persons who satisfied the criteria for authorship but are not listed. We further confirm that all the authors listed in the manuscript have been approved by all of us. Author contributions: All authors contributed to the study conception and design. Material preparation, data collection and analysis were performed by Yongpei Wang and Jieru Yang. The first draft of the manuscript was written by Yongpei Wang and all authors commented on previous versions of the manuscript. All authors read and approved the final manuscript.

Funding: The authors acknowledge support from the Talent Introduction Program of Nanjing Audit University and the Science and Technology Project and Major project of the Social Science Fund of Jiangsu Province (No. 17ZD006).

Competing interests: The authors declare no competing interest.

Availability of data and materials: The datasets used and/or analyzed during the current study are available from the corresponding author on reasonable request.

\section{References}

Barassi, M. R., \&Zhou, Y. (2012). The impact of corruption on FDI: A parametric and non-parametric analysis. European Journal of Political Economy, 28(3), 302- 
Baron, R. M., \&Kenny, D.A.(1986). The moderator-mediator variable distinction in social psychological research: Conceptual, strategic, and statistical considerations. Journal of Personality \& Social Psychology, 51, 1173-1182.

Blackman, A. (2000). Informal sector pollution control: what policy options do we have?. World Development, 28(12), 2067-2082.

Biswas, A. K., Farzanegan, M. R., \&Thum, M. (2012). Pollution, shadow economy and corruption: Theory and evidence. Ecological Economics, 75, 114-125.

Bound, J., Brown, C., \&Mathiowetz, N. (2001).Measurement error in survey data, in J. J. Heckman and E. E. Leamer (eds) Handbook of Econometrics, Vol. 5, pp. 3705-843. Amsterdam: North-Holland. 513-533.

Candau, F., \&Dienesch, E. (2017). Pollution haven and corruption paradise. Journal of Environmental Economics and Management,85,171-192.

Cadoret, I., \&Padovano, F., (2016). The political drivers of renewable energies policies. Energy Econ. 56, $261-269$.

Cole, M. A. (2007). Corruption, income and the environment: an empirical analysis. Ecological Economics, 62(3-4), 637-647. economics and management, 46(3), 490-512.

Damania, R. (2002). Environmental controls with corrupt bureaucrats. Environmental and Development Economics, 7(3), 407-427.

Dutta, N., Kar, S., Saha, S. (2017). Human capital and FDI: How does corruption affect the relationship? Economic Analysis and Policy, 56, $126-134$. 
Egger, P., \&Winner, H. (2005). Evidence on corruption as an incentive for foreign direct investment. European Journal of Political Economy, 21(4), 932-952.

Fredriksson, P. G., \&Svensson, J. (2003). Political instability, corruption and policy formation: the case of environmental policy. Journal of public economics, 87(7-8), $1383-1405$.

Glaeser, E. L., \&Saks, R. E. (2006). Corruption in America. Journal of public Economics, 90(6-7), 1053-1072.

Gennaioli, C. , \&Tavoni, M. (2016). Clean or dirty energy: evidence of corruption in the renewable energy sector. Public Choice, 166(3-4), 261-290.

Gisladottir, J. , Sigurgeirsdottir, S. , Stjernquist, I. , \&Ragnarsdottir, K. V. (2020). Corruption risks in renewable resource governance: case studies in Iceland and Romania. Politics and Governance, 8(2):167-179.

Grossman, G. M., \&Krueger, A. B. (1991). Environmental impacts of a North American free trade agreement (No. w3914). National Bureau of economic research.

Hao, Y., Gai, Z., Yan, G., Wu, H., \&Irfan, M. (2021). The spatial spillover effect and nonlinear relationship analysis between environmental decentralization, government corruption and air pollution: Evidence from China. Science of The Total Environment, 763, 144183.

Hassaballa, H. (2015). The effect of corruption on carbon dioxide emissions in the MENA region. European Journal of Sustainable Development, 4(2), 301-301.

Hao, Y., Gai, Z., \&Wu, H. (2020). How do resource misallocation and government corruption affect green total factor energy efficiency? Evidence from China. Energy Policy, 143, 111562.

Huang, Z., Zheng, W., Tan, X., Zhang, X., \&Liu, L. (2016). Polluted air increases perceived corruption. Journal of Pacific Rim Psychology, 10.

International Monetary Fund(IMF).(2016). Corruption : costs and mitigating strategies. https://www.imf.org/en/Publications/Staff-DiscussionNotes/Issues/2016/12/31/Corruption-Costs-and-Mitigating-Strategies-43888.

Ivanova, K. (2011). Corruption and air pollution in Europe. Oxford Economic Papers, 63(1), 49-70. 
Jabeur, S. B., \&Sghaier, A. (2018). The relationship between energy, pollution, economic growth and corruption: A Partial Least Squares Structural Equation Modeling (PLS-SEM) approach. Economics Bulletin, 38(4), 1927-1946.

Kampa, M., \&Castanas, E. (2008). Human health effects of air pollution. Environmental pollution, 151(2), $362-367$.

Kolstad, I., Søreide, T.,\& Williams, A. (2008). Corruption in natural resource management: An introduction. U4 Brief. Retrieved from https://www.cmi.no/publications/2936-corruptionin-natural-resource-management-an

Lambsdorff, J. G. (2003). How corruption affects productivity. Kyklos, 56(4), 457-474.

Liu, Y., \&Dong, F. (2021). Haze pollution and corruption: A perspective of mediating and moderating roles. Journal of Cleaner Production, 279 , 123550.

Liu, Y., \&Dong, F. (2020). Corruption, economic development and haze pollution: Evidence from 139 global countries. Sustainability, $12(9)$, 3523.

Liao, X., Dogan, E., \&Baek, J. (2017). Does corruption matter for the environment? Panel evidence from China. Economics: The Open-Access, Open-Assessment EJournal, 11(27), 1-12.

Lisciandra, M., \&Migliardo, C. (2017). An empirical study of the impact of corruption on environmental performance: Evidence from panel data. Environmental and Resource Economics, 68(2), 297-318.

Lopez, R., \&Mitra, S. (2000). Corruption, pollution, and the Kuznets environment curve. Journal of Environmental Economics and Management, 40(2), 137-150.

Leitão, A. (2010). Corruption and the environmental Kuznets curve: empirical evidence for sulfur. Ecological Economics, 69(11), $2191-2201$.

MacKinnon, D.P., Fairchild, A.J., \&Fritz, M.S. (2007). Mediation analysis. Annual Review of Psychology, 58, $593-614$.

Mauro, P. (1995). Corruption and growth. The quarterly journal of economics, 110(3), 681-712.

Morse, S. (2006). Is corruption bad for environmental sustainability? A cross-national analysis. Ecology and Society, 11(1). 
Nicolli, F., \& Vona, F.,( 2015). The evolution of renewable energy policy in OECD countries: Aggregate indicators and determinants. In: Schneider, F., Kollmann, A., Reichl, J. (Eds.),Political Economy and Instruments of Environmental Politics. MIT Press, Boston ,pp. 117-148

Oniango,M.(2020). Corruption is hindering the global transition to renewable energy. https://iaccseries.org/blog/corruption-is-hindering-the-global-transition-torenewable-energy/

Olken, B. A., \&Pande, R. (2012). Corruption in developing countries. Annu. Rev. Econ., 4(1), 479-509.

Pellegrini, L., \&Gerlagh, R. (2006). Corruption and environmental policies: what are the implications for the enlarged EU? European Environment, 16(3), 139-154.

Ramón López, \& Mitra, A. S. (2000). Corruption, pollution, and the Kuznets environment curve. Journal of Environmental Economics \& Management, 40(2), 137150 .

Rehman, F. U., Nasir, M.,\& Kanwal, F.(2012). Nexus between corruption and regional Environmental Kuznets curve: the case of South Asian countries. Environment, development and sustainability, 14(5), 827-841.

Sarmidi, T. , Nor, A. H. S. M. , \&Ridzuan, S. (2015). Environmental stringency, corruption and foreign direct investment (FDI): lessons from global evidence. Asian Academy of Management Journal of Accounting and Finance, 11(1), 85-96.

Sahli, I., \&Rejeb, J. B. (2015). The environmental Kuznets curve and corruption in the MENA region. Procedia-Social and Behavioral Sciences, $195,1648-1657$.

Sekrafi, H., \&Sghaier, A. (2016). Examining the relationship between corruption, economic growth, environmental degradation, and energy consumption: a panel analysis in MENA region. J. Knowl. Econ. 1-17.

Stern, D.I., (2012). Modeling international trends in energy efficiency. Energy Econ. 34 (6),2200-2208.

Sulemana, I., \&Kpienbaareh, D. (2020). Corruption and air pollution: a comparative study of African and OECD countries. Air Quality, Atmosphere \& Health, 13(12), 


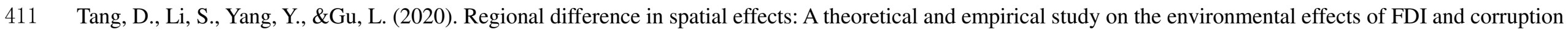
412 in China. Discrete Dynamics in Nature and Society, 2020.

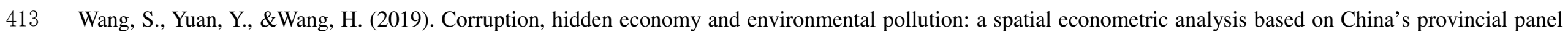
414 data. International journal of environmental research and public health, 16(16), 2871.

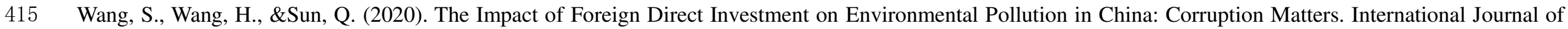
416 Environmental Research and Public Health, 17(18), 6477. Walter, M.,\& Luebke, M. (2013). The impact of corruption on climate change: threatening emissions trading mechanisms?. UNEP Global Environmental Alert System, 418 March

419 Welsch, H. (2004). Corruption, growth, and the environment: a cross-country analysis. Environment and Development Economics, 663-693.

420 Wooldridge, J. M. (2002). Econometric analysis of cross section and panel data. Cambridge, MA: The MIT Press.

421 Wooldridge, J. M. (2006). Introductory Econometrics: A Modern Approach, 3rd edn. Mason, OH: Thomson-South Western.

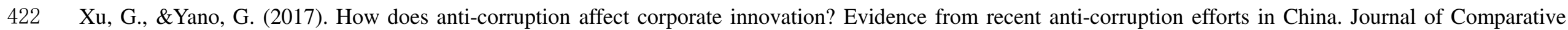
423 Economics, 45(3), 498-519.

424 Yap, H. T. (2006). Corruption begets pollution. Marine Pollution Bulletin, 52(10), 1121-1122.

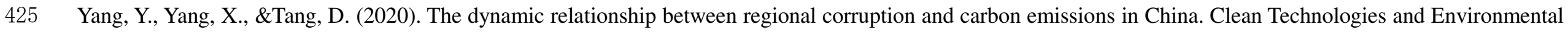
426 Policy, 1-14. 
Zhang, Y. J., Jin, Y. L., Chevallier, J., \&Shen, B. (2016). The effect of corruption on carbon dioxide emissions in APEC countries: a panel quantile regression analysis.

Technological Forecasting and Social Change, 112, 220-227.

Zhou,M., Wang, B.,\& Chen,Z. (2020).Has the anti-corruption campaign decreased air pollution in China? Energy Economics,91, 104878.

1


Table 1

$446 \quad$ Statistical summary

\begin{tabular}{|c|c|c|c|c|c|}
\hline Variable & Observations & Mean & Standard deviation & Minimum & Maximum \\
\hline lnco & 1,940 & 10.5137 & 1.9389 & 6.3556 & 16.1502 \\
\hline Incop & 1,940 & 0.8860 & 1.3602 & -4.0584 & 3.5861 \\
\hline lncoi & 1,940 & -0.7776 & 0.7954 & -3.0171 & 1.8617 \\
\hline Corr & 1,940 & 0.0510 & 1.0301 & -2.0575 & 2.5856 \\
\hline lngdpp & 1,940 & 8.5743 & 1.4277 & 5.2293 & 11.4251 \\
\hline lnind & 1,940 & 3.3960 & 0.2806 & 2.3209 & 4.3492 \\
\hline $\operatorname{lnfos}$ & 1,940 & 4.0673 & 0.6836 & 0.4945 & 4.6051 \\
\hline enxp & 1,940 & -7.2555 & 163.6621 & -1942.00 & 99.0853 \\
\hline Inren & 1,940 & 2.6983 & 1.5070 & -5.1736 & 4.5885 \\
\hline
\end{tabular}


Table 2

456 Correlation coefficients

\begin{tabular}{|c|c|c|c|c|c|c|c|c|c|}
\hline & $\operatorname{lnco}$ & lncop & lncoi & Corr & lnren & $\operatorname{lnfos}$ & $\operatorname{lngdpp}$ & lnind & enxp \\
\hline lnco & 1.0000 & & & & & & & & \\
\hline lncop & 0.6392 & 1.0000 & & & & & & & \\
\hline lncoi & 0.2009 & 0.2099 & 1.0000 & & & & & & \\
\hline Corr & 0.2952 & 0.5892 & -0.4763 & 1.0000 & & & & & \\
\hline Inren & -0.4662 & -0.6566 & -0.3918 & -0.1896 & 1.0000 & & & & \\
\hline $\operatorname{lnfos}$ & 0.5006 & 0.7688 & 0.3884 & 0.2772 & -0.5938 & 1.0000 & & & \\
\hline lngdpp & 0.4950 & 0.8372 & -0.3585 & 0.8294 & -0.4086 & 0.5170 & 1.0000 & & \\
\hline lnind & 0.2553 & 0.2985 & 0.2356 & -0.0850 & -0.3521 & 0.3293 & 0.1485 & 1.0000 & \\
\hline enxp & 0.0421 & 0.0591 & 0.0916 & 0.1206 & 0.0325 & 0.0754 & 0.0068 & -0.4259 & 1.0000 \\
\hline
\end{tabular}


Table 3

467 Estimation results of the total effect(path $\beta$ )

\begin{tabular}{|c|c|c|c|}
\hline & Model1 & Model2 & Model3 \\
\hline & $E=\operatorname{lnco}$ & $E=\operatorname{lncop}$ & $E=\operatorname{lncoi}$ \\
\hline \multirow[t]{2}{*}{ Corr } & $-0.3908 * * *$ & $-0.1517 * * *$ & $-0.1542 * * *$ \\
\hline & $(0.0688)$ & $(0.0220)$ & $(0.0220)$ \\
\hline \multirow[t]{2}{*}{ lngdpp } & $0.7125 * * *$ & $0.6797 * * *$ & $-0.3160 * * *$ \\
\hline & $(0.0548)$ & $(0.0175)$ & $(0.0175)$ \\
\hline \multirow[t]{2}{*}{ lnind } & $0.8470 * * *$ & $0.3997 * * *$ & $0.3679 * * *$ \\
\hline & $(0.1567)$ & $(0.0502)$ & $(0.0502)$ \\
\hline \multirow[t]{2}{*}{$\operatorname{lnfos}$} & $0.6783 * * *$ & $0.7941 * * *$ & $0.7969 * * *$ \\
\hline & $(0.0677)$ & $(0.0217)$ & $(0.0217)$ \\
\hline \multirow[t]{2}{*}{ enxp } & $0.0012 * * *$ & $0.0006 * * *$ & $0.0006 * * *$ \\
\hline & $(0.0002)$ & $(0.0001)$ & $(0.0001)$ \\
\hline \multirow[t]{2}{*}{ cons } & $-1.2028 * *$ & $-9.5166^{* * * *}$ & $-2.5468 * * *$ \\
\hline & $(0.5364)$ & $(0.1718)$ & $(0.1717)$ \\
\hline Obs & 1940 & 1940 & 1940 \\
\hline
\end{tabular}

Note:***,**, and $*$ refer to significance at $1 \%, 5 \%$, and $10 \%$ confidence level, respectively 
Table 4

471 Estimation results with mediator regressed on $\operatorname{Corr}$ (path $\gamma$ )

\begin{tabular}{|c|c|c|c|c|c|c|}
\hline lnren & Coef & Std. Err. & $\mathrm{t}$ & $\mathrm{P}>|\mathrm{t}|$ & \multicolumn{2}{|c|}{ [95\% Conf. Interval] } \\
\hline Corr & $0.2499 * * *$ & 0.0514 & 4.8607 & 0.0000 & 0.1491 & 0.3507 \\
\hline lngdpp & $-0.3212 * * *$ & 0.0409 & -7.8484 & 0.0000 & -0.4014 & -0.2409 \\
\hline lnind & $-0.8609 * * *$ & 0.1171 & -7.3532 & 0.0000 & -1.0905 & -0.6313 \\
\hline $\operatorname{lnfos}$ & $-0.9467 * * *$ & 0.0506 & -18.7197 & 0.0000 & -1.0459 & -0.8475 \\
\hline enxp & -0.0002 & 0.0002 & -1.0848 & 0.2780 & -0.0006 & 0.0002 \\
\hline cons & $12.2118 * * *$ & 0.4008 & 30.4696 & 0.0000 & 11.4258 & 12.9978 \\
\hline
\end{tabular}

Note:***,**, and $*$ refer to significance at $1 \%, 5 \%$, and $10 \%$ confidence level, respectively

Table 5

Estimation results of the direct effect(path $\lambda$ and $\left.\beta^{\prime}\right)$

\begin{tabular}{|c|c|c|c|}
\hline & Model1 & Model2 & Model3 \\
\hline & $E=\operatorname{lnco}$ & $E=\operatorname{lncop}$ & $E=\operatorname{lncoi}$ \\
\hline lnren & $-0.2351 * * *$ & $-0.1863 * * *$ & $-0.1882 * * *$ \\
\hline
\end{tabular}




\begin{tabular}{|c|c|c|c|}
\hline & $(0.0300)$ & (0.0088) & $(0.0088)$ \\
\hline \multirow[t]{2}{*}{ Corr } & $-0.3321 * * *$ & $-0.1052 * * *$ & $-0.1071 * * *$ \\
\hline & $(0.0682)$ & $(0.0200)$ & $(0.0199)$ \\
\hline \multirow[t]{2}{*}{ lngdpp } & $0.6370 * * *$ & $0.6198 * * *$ & $-0.3764 * * *$ \\
\hline & $(0.0548)$ & $(0.0160)$ & $(0.0160)$ \\
\hline \multirow[t]{2}{*}{ lnind } & $0.6446^{* * *}$ & $0.2393 * * *$ & $0.2059 * * *$ \\
\hline & $(0.1565)$ & $(0.0458)$ & $(0.0457)$ \\
\hline \multirow[t]{2}{*}{ lnfos } & $0.4558 * * *$ & $0.6178 * * *$ & $0.6187 * * *$ \\
\hline & (0.0724) & $(0.0212)$ & $(0.0212)$ \\
\hline \multirow[t]{2}{*}{ enxp } & $0.0011 * * *$ & $0.0006 * * *$ & $0.0006 * * *$ \\
\hline & $(0.0002)$ & $(0.0001)$ & $(0.0001)$ \\
\hline \multirow[t]{2}{*}{ cons } & $1.6681 * * *$ & $-7.2418 * * *$ & -0.2485 \\
\hline & $(0.6426)$ & $(0.1883)$ & $(0.1878)$ \\
\hline obs & 1940 & 1940 & 1940 \\
\hline
\end{tabular}

Note:***, **, and * refer to significance at $1 \%, 5 \%$, and $10 \%$ confidence level, respectively 
Table 6

486 Results of the Sobel-Goodman mediation tests

\begin{tabular}{|c|c|c|c|}
\hline & $\begin{array}{l}\text { Model1 } \\
E=\text { lnco }\end{array}$ & $\begin{array}{c}\text { Model2 } \\
E=\text { lncop }\end{array}$ & $\begin{array}{c}\text { Model3 } \\
E=\text { lncoi }\end{array}$ \\
\hline \multirow[t]{2}{*}{ Sobel } & $-0.0587 * * *$ & $-0.0466^{* * *}$ & $-0.0470 * * *$ \\
\hline & $(0.0142)$ & $(0.0098)$ & $(0.0099)$ \\
\hline \multirow[t]{2}{*}{ Goodman-1 (Aroian) } & $-0.0587 * * *$ & $-0.0466 * * *$ & $-0.0470 * * *$ \\
\hline & $(0.0143)$ & $(0.0098)$ & $(0.0099)$ \\
\hline \multirow[t]{2}{*}{ Goodman-2 } & $-0.0587 * * *$ & $-0.0466 * * *$ & $-0.0470^{* * *}$ \\
\hline & $(0.0141)$ & $(0.0098)$ & $(0.0099)$ \\
\hline \multirow[t]{2}{*}{$\gamma$ coefficient } & $0.2499 * * *$ & $0.2499 * * *$ & $0.2499 * * *$ \\
\hline & $(0.0514)$ & $(0.0514)$ & $(0.0514)$ \\
\hline \multirow[t]{2}{*}{$\lambda$ coefficient } & $-0.2351 * * *$ & $-0.1863 * * *$ & $-0.1882 * * *$ \\
\hline & $(0.0300)$ & $(0.0088)$ & $(0.0088)$ \\
\hline \multirow[t]{2}{*}{ Indirect effect } & $-0.0587 * * *$ & $-0.0466 * * *$ & $-0.0470 * * *$ \\
\hline & $(0.0142)$ & $(0.0098)$ & $(0.0099)$ \\
\hline \multirow[t]{2}{*}{ Direct effect } & $-0.3321 * * *$ & $-0.1052 * * *$ & $-0.1071 * * *$ \\
\hline & $(0.0682)$ & $(0.0200)$ & $(0.0199)$ \\
\hline
\end{tabular}




\begin{tabular}{|c|c|c|c|c|c|c|}
\hline \multicolumn{3}{|c|}{ Total effect } & $-0.3908 * * *$ & \multicolumn{2}{|c|}{$-0.1517 * * *$} & $-0.1542 * * *$ \\
\hline & & & $(0.0688)$ & \multicolumn{2}{|c|}{$(0.0220)$} & $(0.0220)$ \\
\hline \multicolumn{3}{|c|}{ Proportion of total effect that is mediated } & 0.1503 & \multicolumn{2}{|c|}{0.3069} & 0.3050 \\
\hline \multicolumn{3}{|c|}{ Ratio of indirect to direct effect } & 0.1769 & \multicolumn{2}{|c|}{0.4427} & 0.4389 \\
\hline \multicolumn{3}{|c|}{ Ratio of total to direct effect } & 1.1769 & \multicolumn{2}{|c|}{1.4427} & 1.4389 \\
\hline \multicolumn{7}{|c|}{ Note: $* * *, * *$, and $*$ refer to significance at $1 \%, 5 \%$, and $10 \%$ confidence level, respectively } \\
\hline \multicolumn{7}{|l|}{ Table 7} \\
\hline \multicolumn{7}{|c|}{ Robustness check: FE vs. FE-IV } \\
\hline & \multicolumn{3}{|c|}{$\mathrm{FE}$} & \multicolumn{3}{|c|}{ FE-IV } \\
\hline & Model1 & Model2 & Model3 & Model1 & Model2 & Model3 \\
\hline & $E=\ln c o$ & $E=\ln c o p$ & $E=\ln c o i$ & $E=\ln c o$ & $E=\operatorname{lncop}$ & $E=\ln c o i$ \\
\hline \multirow[t]{2}{*}{ Corr } & $-0.0988^{* * *}$ & -0.0183 & -0.0174 & $-0.3502^{* * *}$ & $-0.1512^{* * *}$ & $-0.1473^{* * * *}$ \\
\hline & $(0.0171)$ & $(0.0146)$ & $(0.0146)$ & $(0.0582)$ & $(0.0498)$ & $(0.0497)$ \\
\hline \multirow[t]{2}{*}{ lnren } & $-0.2653^{* * *}$ & $-0.2529^{* * *}$ & $-0.2515^{* * *}$ & $-0.2479^{* * *}$ & $-0.2392^{* * *}$ & $-0.2378^{* * *}$ \\
\hline & $(0.0154)$ & $(0.0132)$ & $(0.0131)$ & $(0.0179)$ & $(0.0153)$ & $(0.0153)$ \\
\hline \multirow[t]{2}{*}{$\operatorname{lngdpp}$} & $0.6020^{* * *}$ & $0.4221^{* * *}$ & $-0.5781^{* * *}$ & $0.6843^{* * *}$ & $0.4824^{* * *}$ & $-0.5172^{* * *}$ \\
\hline & $(0.0171)$ & $(0.0146)$ & $(0.0146)$ & $(0.0218)$ & $(0.0186)$ & $(0.0186)$ \\
\hline
\end{tabular}




\begin{tabular}{|c|c|c|c|c|c|c|}
\hline \multirow[t]{2}{*}{ lnind } & $0.1451^{* * *}$ & $0.1541^{* * *}$ & $0.1586^{* * *}$ & $0.0909^{* *}$ & $0.1495^{* * *}$ & $0.1592^{* * *}$ \\
\hline & $(0.0317)$ & $(0.0271)$ & $(0.0271)$ & $(0.0371)$ & $(0.0317)$ & $(0.0317)$ \\
\hline \multirow[t]{2}{*}{$\operatorname{lnfos}$} & $0.9229^{* * *}$ & $0.7218^{* * *}$ & $0.7201^{* * *}$ & $1.0685^{* * *}$ & $0.8488^{* * *}$ & $0.8451^{* * *}$ \\
\hline & $(0.0347)$ & $(0.0297)$ & $(0.0297)$ & $(0.0392)$ & $(0.0335)$ & $(0.0335)$ \\
\hline \multirow[t]{2}{*}{ enxp } & $0.0004^{* * *}$ & $0.0001^{*}$ & 0.0000827 & $0.0006^{* * *}$ & $0.0003^{* * *}$ & $0.0003^{* * *}$ \\
\hline & $(0.0001)$ & $(0.0001)$ & $(0.0001)$ & $(0.0001)$ & $(0.0001)$ & $(0.0001)$ \\
\hline \multirow[t]{2}{*}{ cons } & $1.8291^{* * *}$ & $-5.5080^{* * *}$ & $1.3919^{* * *}$ & $0.6813^{* * *}$ & $-6.5645^{* * *}$ & 0.3205 \\
\hline & $(0.2089)$ & $(0.1788)$ & $(0.1787)$ & $(0.2617)$ & $(0.2237)$ & $(0.2233)$ \\
\hline \multirow{2}{*}{\multicolumn{2}{|c|}{ Sargan test }} & & & 2.766 & 0.745 & 0.627 \\
\hline & & & & $(0.0963)$ & $(0.3882)$ & $(0.4283)$ \\
\hline obs & 1,940 & 1,940 & 1,940 & 1,552 & 1,552 & 1,552 \\
\hline
\end{tabular}

Note:***,**, and $*$ refer to significance at $1 \%, 5 \%$, and $10 \%$ confidence level, respectively 
Table 8

502 Robustness check: FE-IV estimation results with heterogeneous country groups

\begin{tabular}{|c|c|c|c|c|c|c|}
\hline & \multirow{2}{*}{\multicolumn{2}{|c|}{$\begin{array}{l}\text { Model1 } \\
E=\operatorname{lnco}\end{array}$}} & \multirow{2}{*}{\multicolumn{2}{|c|}{$\begin{array}{c}\text { Model2 } \\
E=\operatorname{lncop}\end{array}$}} & \multirow{2}{*}{\multicolumn{2}{|c|}{$\begin{array}{l}\text { Model3 } \\
E=\text { lncoi }\end{array}$}} \\
\hline & & & & & & \\
\hline & ingroup $==1$ & ingroup $==0$ & ingroup $==1$ & ingroup $==0$ & ingroup $==1$ & ingroup $==0$ \\
\hline \multirow[t]{2}{*}{ Corr } & 0.0817 & $-0.4109^{* * *}$ & 0.0363 & $-0.0630^{* * *}$ & 0.0399 & $-0.0593^{* *}$ \\
\hline & $(0.0515)$ & $(0.0709)$ & $(0.0479)$ & $(0.0244)$ & $(0.0474)$ & $(0.0243)$ \\
\hline \multirow[t]{2}{*}{ lngdpp } & $0.6118^{* * *}$ & $0.6856^{* * * *}$ & $0.2301^{* * *}$ & $0.4601^{* * *}$ & $-0.7575^{* * *}$ & $-0.5407^{* * *}$ \\
\hline & $(0.0712)$ & $(0.0241)$ & $(0.0662)$ & $(0.0163)$ & $(0.0655)$ & $(0.0163)$ \\
\hline \multirow[t]{2}{*}{ lnind } & $0.2428^{* * *}$ & $0.0939^{* *}$ & $0.3875^{* * *}$ & $0.1257^{* * *}$ & $0.4220^{* * *}$ & $0.1301^{* * *}$ \\
\hline & $(0.0845)$ & $(0.0414)$ & $(0.0786)$ & $(0.0301)$ & $(0.0777)$ & $(0.0301)$ \\
\hline \multirow[t]{2}{*}{$\operatorname{lnfos}$} & $0.9410^{* * *}$ & $1.0348^{* * *}$ & $1.1530^{* * *}$ & $0.7594^{* * *}$ & $1.1308^{* * *}$ & $0.7569^{* * *}$ \\
\hline & $(0.1394)$ & $(0.0432)$ & $(0.1297)$ & $(0.0324)$ & $(0.1283)$ & $(0.0323)$ \\
\hline \multirow[t]{2}{*}{ enxp } & $0.0013^{* * *}$ & $0.0005^{\text {*** }}$ & $0.0006^{* * * *}$ & $0.0002^{* * *}$ & $0.0006^{* * * *}$ & $0.0002^{* * *}$ \\
\hline & $(0.0002)$ & $(0.0001)$ & $(0.0002)$ & $(0.0001)$ & $(0.0002)$ & $(0.0001)$ \\
\hline \multirow[t]{2}{*}{ Inren } & $-0.1209^{* * *}$ & $-0.2939^{* * *}$ & $-0.1084^{* * *}$ & $-0.2793^{* * * *}$ & $-0.1035^{* * *}$ & $-0.2804^{* * *}$ \\
\hline & $(0.0216)$ & $(0.0242)$ & $(0.0200)$ & $(0.0182)$ & $(0.0198)$ & $(0.0182)$ \\
\hline cons & 0.8204 & $0.8522^{* * *}$ & $-6.3730^{* * *}$ & $-5.8287^{* * *}$ & 0.3687 & $1.0883^{* * *}$ \\
\hline
\end{tabular}




\begin{tabular}{|c|c|c|c|c|c|c|}
\hline & $(0.9836)$ & $(0.2962)$ & $(0.9146)$ & $(0.2044)$ & $(0.9048)$ & $(0.2042)$ \\
\hline \multirow{2}{*}{ Sargan test } & 1.166 & 2.369 & 0.411 & 3.483 & 0.373 & 0.396 \\
\hline & $(0.2803)$ & $(0.1237)$ & $(0.5215)$ & $(0.0620)$ & $(0.5413)$ & $(0.5294)$ \\
\hline obs & 342 & 1,248 & 342 & 1,404 & 342 & 1,404 \\
\hline
\end{tabular}

Note:***,**, and * refer to significance at $1 \%, 5 \%$, and $10 \%$ confidence level, respectively
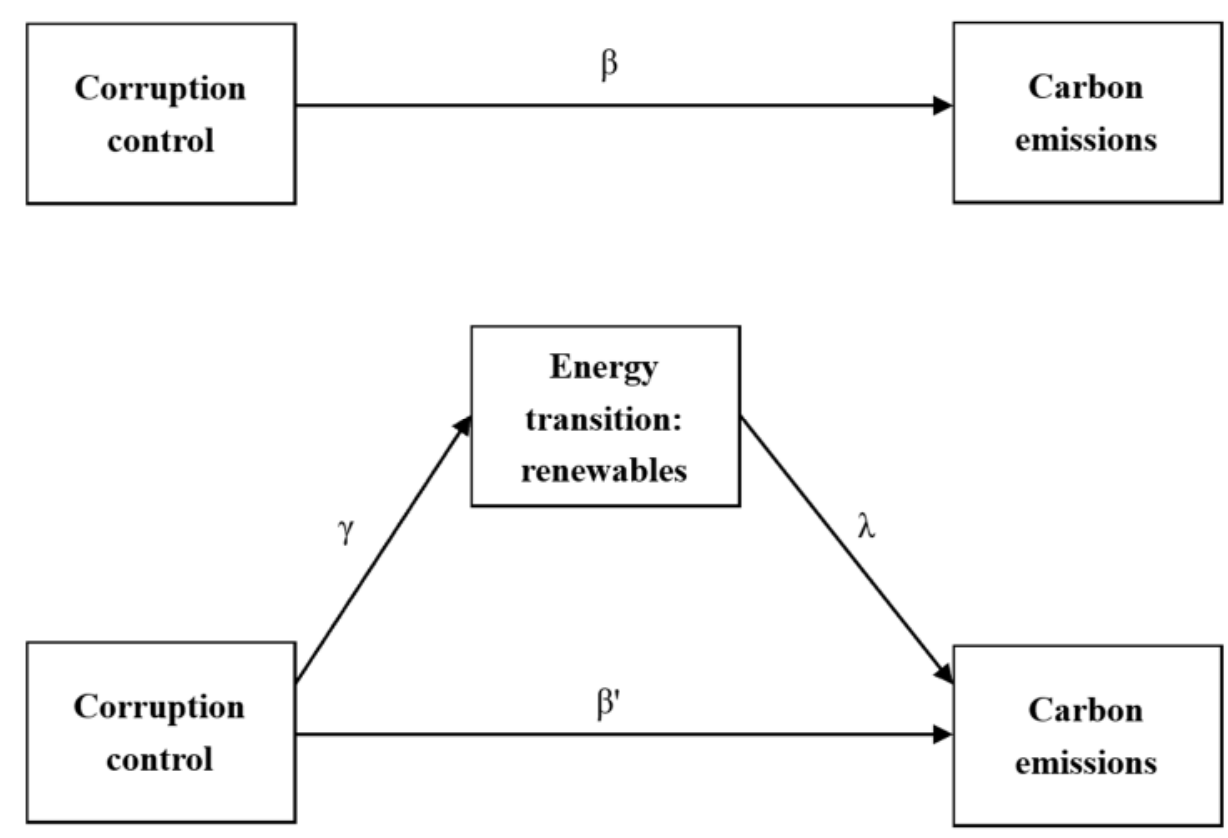

Fig.1 Path diagram for mediation effect model 


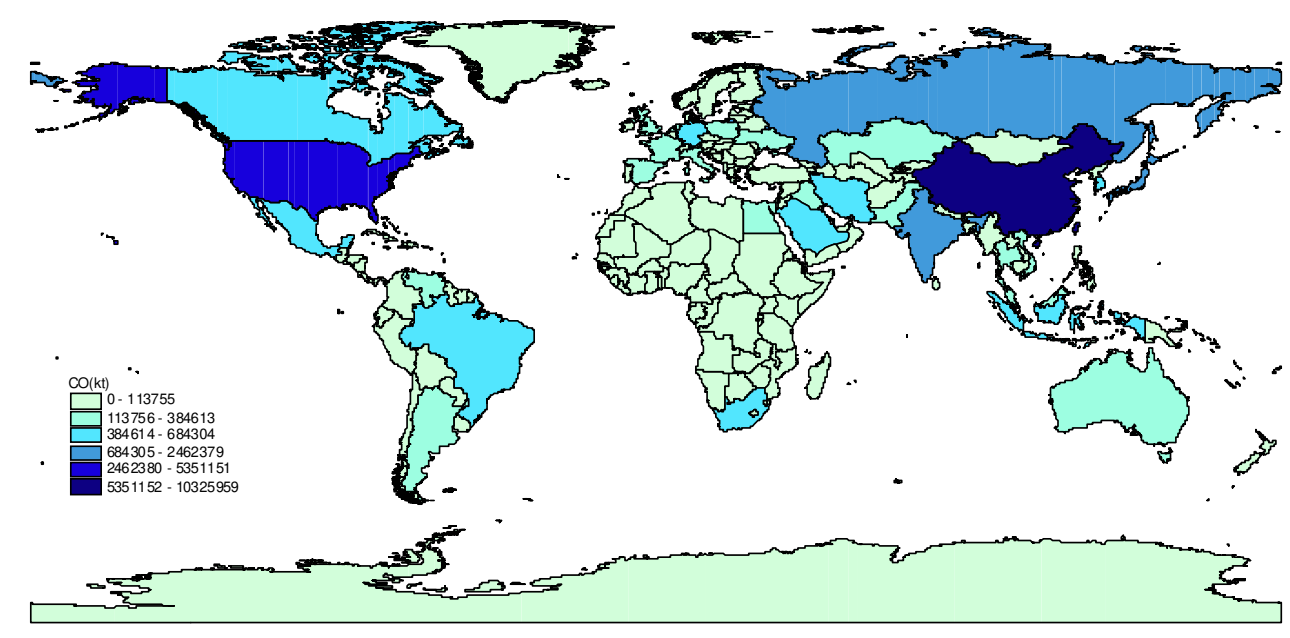

(a) Total carbon emissions

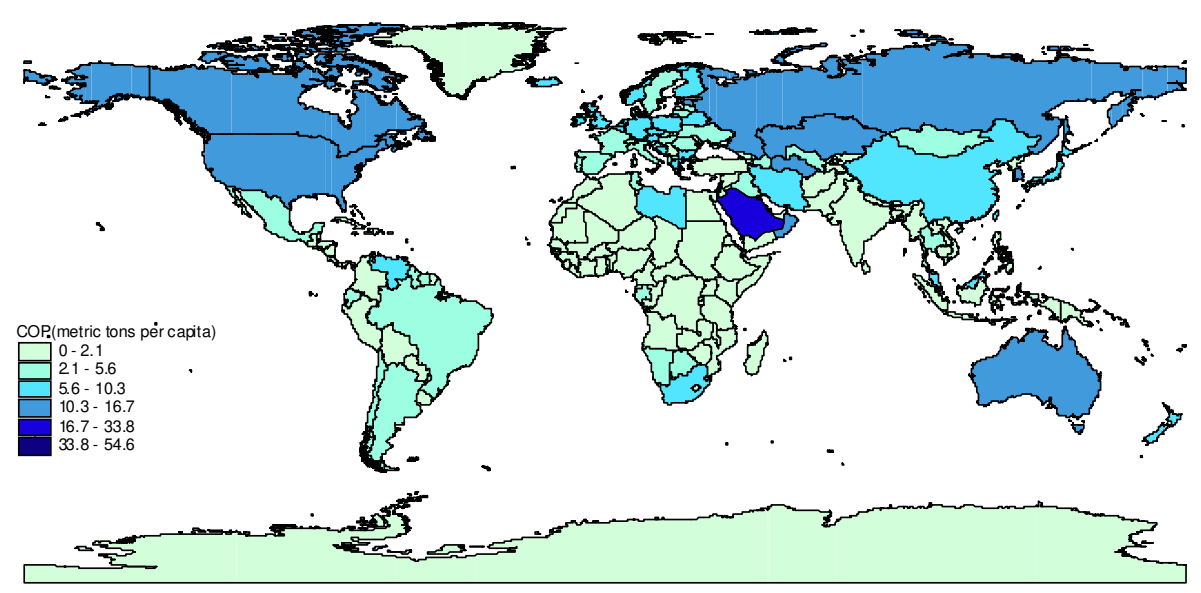

(b) Carbon emissions per capita

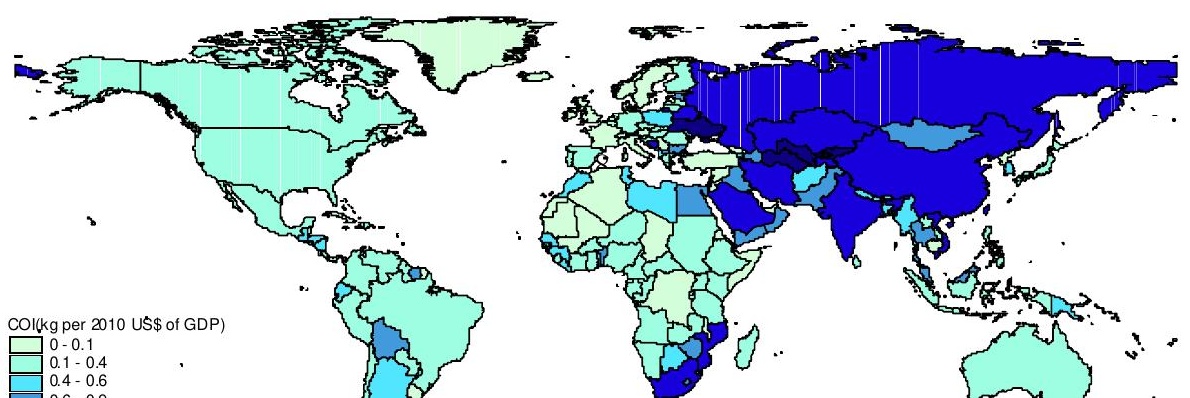




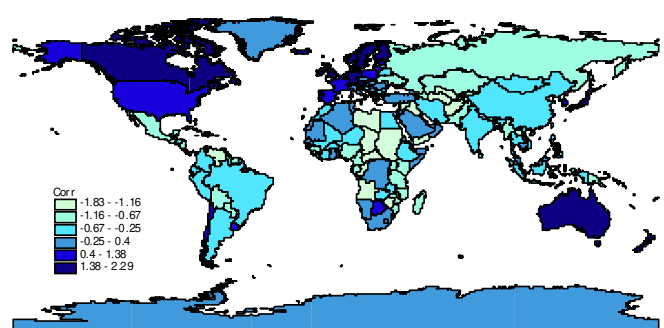

(a) Corrpution control

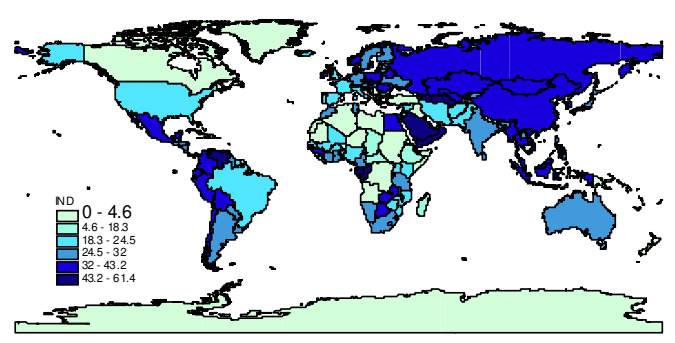

(c) Industry value added (\% of GDP)

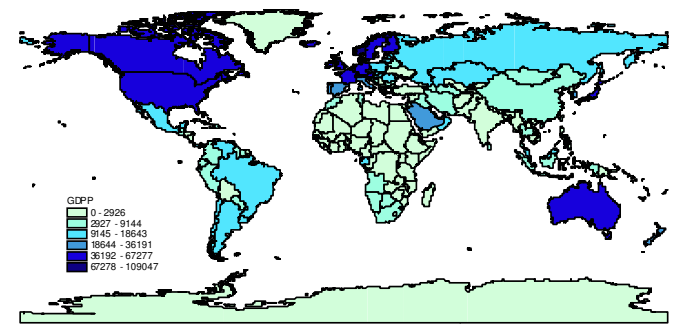

(b) GDP per capita

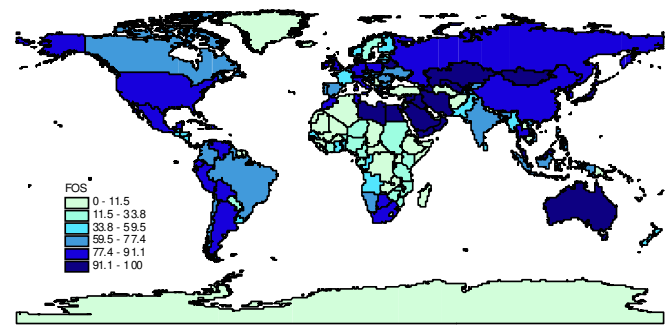

(d) Fossil fuel energy consumption ( \% of total)

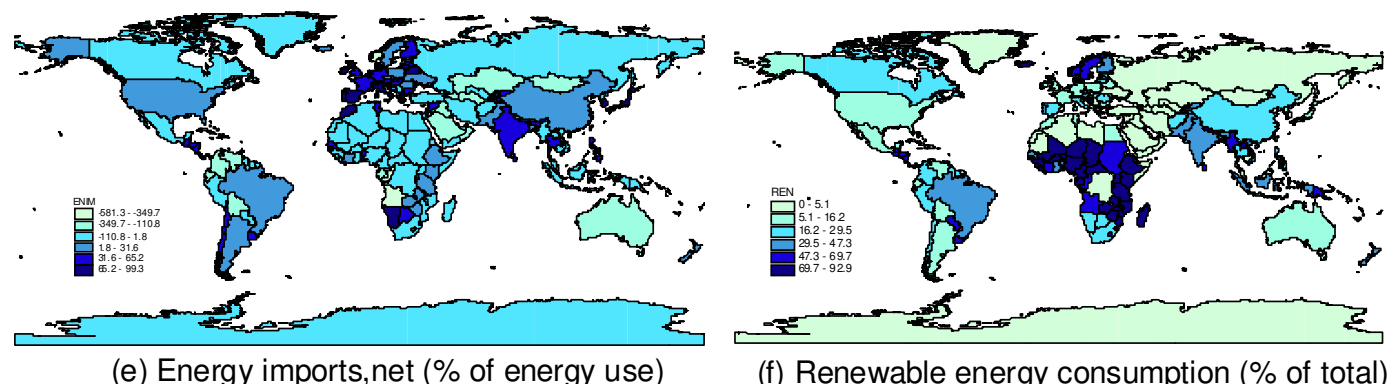

Fig. 3 The explanatory and control variables across countries and regions 